\title{
ASSESSMENT OF TISSUE OPTICAL CLEARING AS A FUNCTION OF GLUCOSE CONCENTRATION USING OPTICAL COHERENCE TOMOGRAPHY
}

\author{
NARENDRAN SUDHEENDRAN ${ }^{\star}$, MOHAMED MOHAMED ${ }^{\dagger}$, MOHAMAD G. GHOSN $^{\dagger}, \ddagger$, \\ VALERY V. TUCHIN $\$, \uparrow$, and KIRILL V. LARIN ${ }^{\star}, \dagger, \S, \|$ \\ * Department of Electrical and Computer Engineering, University of Houston, N308 Engineering \\ Building 1, Houston, TX 77204, USA \\ † Department of Biomedical Engineering, University of Houston, 2028 SERC Building, Houston, \\ TX 77204, USA \\ ‡ Department of Medicine, Baylor College of Medicine, Houston, TX 77030, USA \\ $\S$ Institute of Optics and Biophotonics, Saratov State University, Saratov 410012, Russia \\ II Institute of Precise Mechanics and Control of RAS, Saratov 410056, Russia
}

\begin{abstract}
One of the major challenges in imaging biological tissues using optical techniques, such as optical coherence tomography (OCT), is the lack of light penetration due to highly turbid structures within the tissue. Optical clearing techniques enable the biological samples to be more optically homogeneous, allowing for deeper penetration of light into the tissue. This study investigates the effect of optical clearing utilizing various concentrations of glucose solution $(10 \%, 30 \%$, and $50 \%$ ) on porcine skin. A gold-plated mirror was imaged beneath the tissue and percentage clearing was determined by monitoring the change in reflected light intensity from the mirror over time. The ratio of percentage clearing per tissue thickness for $10 \%, 30 \%$ and $50 \%$ glucose was determined to be $4.7 \pm 1.6 \% \mathrm{~mm}^{-1}(n=6), 10.6 \pm 2.0 \% \mathrm{~mm}^{-1}(n=7)$ and $21.8 \pm 2.2 \% \mathrm{~mm}^{-1}(n=$ 5 ), respectively. It was concluded that while higher glucose concentration has the highest optical clearing effect, a suitable concentration should be chosen for the purpose of clearing, considering the osmotic stress on the tissue sample.
\end{abstract}

\section{Keywords}

Glucose; porcine skin; percent clearing; scattering coefficient; optical coherence tomography

\section{Introduction}

Optical coherence tomography (OCT) has become popular as a tissue imaging and diagnostic technique during the past two decades. ${ }^{1-3}$ OCT performs axial imaging by following the principles of low-coherence interferometry (LCI), ${ }^{4}$ using a broadband laser source (typically operating in NIR spectral range), an interferometer (usually a Michelson interferometer), and a detection device (such as a photodetector, CCD array). Transverse scanning of the laser beam across tissue surface using galvanometer mirrors allows

(c) World Scientific Publishing Company

"Corresponding author. klarin@uh.edu. 
reconstructing 2D and 3D images. With an axial resolution of $\sim 2-20 \mu \mathrm{m},{ }^{1,2}$ OCT is advantageous compared to existing non-optical imaging modalities such as magnetic resonance imaging (MRI) and ultrasound imaging in terms of resolution, capability of realtime imaging, and cost. OCT is capable of achieving 2-6 mm imaging depth in biological tissues, ${ }^{5,6}$ still superior compared to other 3D optical imaging modalities such as confocal microscopy or multiphoton microscopy with imaging depths that are less than $500 \mu \mathrm{m}$, making it ideal for sub-surface imaging. However, a major drawback of all optical techniques, including OCT, is the distortion and attenuation of light beam due to scattering and absorption in turbid tissues, which limits the achievable imaging depth. ${ }^{7-10}$

The refractive index (RI) mismatch between the intracellular fluid, cell organelles, extracellular fluid and fiber structures is a major cause for the optical inhomogeneities in tissues, which in turn results in highly scattering media. ${ }^{11,12}$ For example, the skin is a multilayered structure, where each layer contains different components with varying optical properties. ${ }^{8,13,14}$ The presence of melanin $(\mathrm{RI}=1.7)$, fully hydrated collagen $(\mathrm{RI}=1.43)$, adipose tissue $(\mathrm{RI}=1.46)$, and cellular nuclei $(\mathrm{RI}=1.39-1.41)$ on the background of low refractive index of cell cytoplasm and interstitial fluid $(\mathrm{RI}=1.34)$ causes high scattering in the epidermis and the dermis layers of the skin. ${ }^{8,13}$ High scattering in the upper layers of tissues attenuates the light before it can reach the deeper layers, hence, limiting imaging depth of optical imaging techniques.

Recent studies have been aimed at altering turbid biological tissues in such a way that they become more optically transparent while keeping their internal structure intact. . $^{8,12,15}$ These optical clearing techniques can be accomplished by introducing so-called optical clearing agent (OCA) - a chemical compound with distinct osmotic properties such as glucose and glycerol. ${ }^{8-10}$ As the OCA diffuses through the tissue, it replaces water via osmotic forces. ${ }^{8-10}$ This process is responsible for matching the refractive index of the intracellular and extracellular fluids, which results in a more optically homogeneous tissue, thereby reducing the scattering coefficient. ${ }^{8,13}$ Other changes in the scattering properties of the tissue could be due to dehydration of the tissue ${ }^{18}$ or the dissociation of collagen fibers ${ }^{19}$ occurring due to the addition of the OCA.

Previously, the effects of optical clearing and diffusion potency of different OCA agents (such as glucose solution, glycerol, and propylene glycol) and their potential as a function of tissue composition have been studied in different biological tissues such as corneal and sclera of the eye, vasculature, and skin. ${ }^{12,20-30}$ It has been shown that high concentrations of OCAs could potentially constrict and even block blood vessels in applied area and, thus, reduce local delivery of oxygen and nutrients. ${ }^{28}$ Therefore, it is necessary to determine an appropriate concentration of OCA which can cause a required change in contrast in allotted time and having minimal impact on the health of tissue sample. The focus of this study was to investigate the effect of optical clearing on thick epithelial tissue samples $(\sim 1.5 \mathrm{~mm})$, such as porcine skin, using varying concentrations of glucose in saline $(10 \%, 30 \%$, and $50 \%)$ for duration of up to three hours. A gold-plated mirror positioned beneath the tissue sample was imaged in order to monitor the change in reflected light intensity from the mirror. The percent clearing of the tissue was then correlated to this change in reflected light intensity. Metal reflectors are commonly used to measure back reflectance intensities. They have been employed to assess the optical clearing of blood based on aggregation and sedimentation of blood cells. ${ }^{31}$ 


\section{Materials and Methods}

\subsection{SS-OCT system}

The swept-source OCT (SS-OCT) system (Fig. 1) employed in this study utilized a broadband swept-source laser (Thorlabs, SL1325-P16) with a wavelength range of $1325 \pm$ $50 \mathrm{~nm}$, which corresponds to an axial resolution of $8 \mu \mathrm{m}$ (in air). The laser swept at a frequency of $16 \mathrm{kHz}$ with an average output power of $10 \mathrm{~mW}$. The imaging depth of the system is $3 \mathrm{~mm}$ (in air) and has a transverse resolution of $15 \mu \mathrm{m}$. A balanced photodetector (Thorlabs, PDB140C) was used to detect the inter-ferogram signal resulting from backscattered light from the sample arm and backreflected light from reference arm of the interferometer. This signal is calibrated into linear k-space using a Mach-Zehnder interferometer (MZI) clock. An in-depth profile (A-scan) was reconstructed by performing fast Fourier transform (FFT) on the calibrated signal. A 2D image was acquired by performing transverse scanning with galvanometer-mounted mirrors. A 2D image consisted of $512 \times 512$ pixels with a scanning range of $1 \times 3 \mathrm{~mm}$ in the $x$ and $z$ direction, respectively.

\subsection{Tissues}

Porcine ears were obtained from a local market. The sections $(1.55 \pm 0.14 \mathrm{~mm})$ of skin samples from the ear were cut into squares $\left(1 \times 1 \mathrm{~cm}^{2}\right)$ and stored in saline to prevent dehydration. The epidermis, dermis and a layer of subcutaneous fat were preserved in the samples. Custom-made gold-plated mirrors $\left(5 \times 5 \mathrm{~mm}^{2}\right)$ were used in these experiments as a reference reflector due to gold's strong back-reflectance characteristic for observing the effect of optical clearing. Glucose solutions were prepared in physiological saline.

Tissue samples were placed in saline solution at room temperature, 30 minutes prior to the onset of the experiment, in order to reach room temperature for the specimen. The mirror was placed in a Petri dish under the tissue sample and the entire setup was fully submerged in saline to preserve hydration of the tissue during the experiment. The skin sample was imaged ensuring the presence of the mirror. Images were recorded every 10 seconds, for a period of 10 minutes to form a baseline. Following the 10-minute period, the saline was removed from the Petri dish and replaced with $10 \%, 30 \%$, or $50 \%$ glucose solutions (prepared from the saline). Imaging was then performed for three hours to monitor the change in the intensity of light reflected by the mirror. Control experiments were performed by imaging skin samples under similar conditions with no addition of glucose for a period of three hours. Mineral oil was added on the surface of solution prior to imaging to minimize evaporation, ensuring minimal change in the focus of the light, which in turn could contribute to the change in intensity. Several trials were performed for each control and concentration of glucose (Control: $n=6 ; 10 \%: n=6 ; 30 \%: n=7 ; 50 \%: n=5$ ) to statistically process experimental data.

\subsection{Data processing}

A MATLAB code was written to calculate the intensity of light reflected from the mirror surface over time. The algorithm detects the maximum intensity within a specified depth region (corresponding to the surface of the mirror) within an A-scan. Similarly, light intensity corresponding to the mirror's surface was determined for all A-scans in a 2D image and averaged together to obtain a single value. This averaged value corresponded to a particular instant of time. The averaged intensity values were obtained for all time instances throughout the duration of the experiment. The obtained intensity values versus time plot were fitted using an exponential fit curve in the form $I(t)=A\left(1-e^{-B t}\right)$, where $I$ is the averaged intensity, $t$ is the time, and $A$ and $B$ are fit parameters. For exponential fitting, averaged intensity values obtained after the addition of glucose were considered and accordingly re-indexed to begin at $t=0$ minutes. Further, all the intensity values of the new 
data set, $I(t)$, were subtracted by the first intensity value $I(0)$, so that the exponential fit is performed on relative changes in intensity over time. For control experiments, a linear fit in the form $I(t)=A t+B$ instead of the exponential fit was used. For a particular glucose concentration, mean value and standard deviation of intensity at an instance in time is obtained from corresponding $n$ exponentially fitted curves at that time instant. The percentage clearing of a trial is determined from the initial intensity ( $I_{\text {initial }}$ at $t=0$ minutes) and final intensity ( $I_{\text {final }}$ at $t=180$ minutes) using Eq. (2).

$$
\text { percentage clearing }=\frac{\left(I_{\text {final }}-I_{\text {initial }}\right)}{I_{\text {initial }}} \times 100 \text {. }
$$

Percentage clearing/thickness ratio was determined for the purpose of normalization with respect to tissue thickness.

\section{Results}

Typical changes in intensity of the light reflected from the gold-plated mirror in experiments with 50\% glucose solution are depicted in Fig. 2. Figure 2(a) presents a 2D image acquired by the SSOCT setup immediately after the addition of 50\% glucose solution ( $t=0$ minutes). It is observed from the figure that the mirror is barely visible as the intensity of light reflected from it is very low. The image depicted in Fig. 2(b) was acquired 35 minutes past the addition of the glucose solution. It is observed from the figure that the intensity of reflected light from the mirror has increased. The continuous rise in the intensity of reflected light from the mirror can be observed from Figs. 2(c)-2(f), which were acquired 70, 105, 140,165 minutes past the addition of glucose solution, respectively. The averaged intensity of mirror as a function of time is shown in Fig. $2(\mathrm{~g})$. The flat region in the plot occurring prior to the addition of glucose solution ( $t=0$ minutes) shows that the intensity of light reflected from the mirror had remained constant, indicating that no optical clearing has occurred due to the presence of saline or mineral oil. However, the reflected light has started to increase soon after the addition of glucose, increasing at an exponential rate while the thickness of tissue sample is decreasing due to osmotic replacement of water.

The exponential fit is performed on intensity values obtained starting from the addition of glucose solution ( $t=0$ minutes) after subtracting all intensity values by $I(0)$, so that the exponential fit is performed on relative changes in intensity. Figure 3 depicts the intensity changes of light reflection from the gold mirror as a function of time and the corresponding exponential fit of a $50 \%$ glucose trial. A $R^{2}$ value of 0.995 indicates a strong correlation between the intensity values and their exponential fit.

The averaged curves of all the glucose concentration along with their respective tissue thickness range are plotted in Fig. 4. It is observed that the rise in intensity is maximal for $50 \%$ glucose trials followed by $30 \%$ glucose solutions and $10 \%$ glucose solutions at any instant of time. The obtained results for the different concentrations can be compared since the tissues used for all glucose concentrations were within a narrow range of thicknesses. The exponential fitting of the experimental data [in the form of $I(t)=A\left(1-e^{-B t}\right)$ ] yielded fitting parameter $A$ (indicating the maximal changes in signal intensity upon saturation) to be equal to $41 \pm 9 \mathrm{~dB}, 15 \pm 4 \mathrm{~dB}$, and $4 \pm 2 \mathrm{~dB}$ for $50 \%, 30 \%$, and $10 \%$ glucose solution, respectively in these experiments. Correspondingly, the fitting parameter $B$ (reciprocal of which indicates the time needed to reach the saturation) is found to be $0.012 \pm 0.005 \mathrm{~min}^{-1}$, $0.032 \pm 0.033 \mathrm{~min}^{-1}$, and $0.043 \pm 0.018 \mathrm{~min}^{-1}$ for $50 \%, 30 \%$, and $10 \%$ glucose solution, respectively. These data clearly indicate that more concentrated solutions give higher 
clearing effect whereas it requires more time to reach the saturation. The small changes in intensity during the control experiments $(\sim 1.5 \mathrm{~dB})$ could be attributed to the change in the focus of the light, which may occur due to little evaporation of solution over 180 minutes of experimentation time.

The percentage clearing was obtained using Eq. (2). The percentage clearing/thickness ratio was determined to be $4.7 \pm 1.6 \% \mathrm{~mm}^{-1}(n=6), 10.6 \pm 2.0 \% \mathrm{~mm}^{-1}(n=7)$ and $21.8 \pm 2.2 \%$ $\mathrm{mm}^{-1}(n=5)$ for $10 \%, 30 \%$ and $50 \%$ glucose solutions, respectively, after a period of 180 minutes, and plotted in Fig. 5. High standard deviation for a particular concentration of glucose is mainly caused by the nonuniformity of thicknesses of studied tissue samples.

\section{Discussion}

The presented results indicate the capability of OCT to monitor and quantify the effects of optical clearing on porcine skin continuously for a period of 180 minutes. The changes in the intensity of light penetrating to deep tissue regions due to optical clearing of bulk tissue are inferred by monitoring the changes in the intensity of reflected light from a gold-plated mirror. Percentage clearing was monitored as a function of intensity changes of reflected light from the mirror over time. The results indicate that the highest optical clearing occurs for $50 \%$ glucose solution, followed by the $30 \%$ and $10 \%$ glucose solutions.

The intensity of reflected light from the mirror gradually increases, as observed in Figs. 2(a)-2(f), indicating that intensity of light penetrating to deeper regions of porcine skin is increasing as the top regions of the tissue are progressively clearing. Further, tissue thickness appears to have decreased through the course of the experiment indicating the dehydration of tissue, which is a potential cause for optical clearing due to better ordering of tissue scatterers (collagen and elastin fibers) and refractive index matching, caused by water (having the lowest refractive index) leaving interstitial space. It was determined that the tissue thickness changed by $\sim 25 \%, \sim 6 \%$ and $\sim 4 \%$ for $50 \%, 30 \%$ and $10 \%$ glucose solutions respectively, over the course of the experiment. Additional refractive index matching, which occurred due to introduction of glucose solution into tissue bulk, is another factor of optical clearing. Percentage clearing/thickness ratio was determined to be $4.7 \pm 1.6 \% \mathrm{~mm}^{-1}(n=6)$, $10.6 \pm 2.0 \% \mathrm{~mm}^{-1}(n=7)$ and $21.8 \pm 2.2 \% \mathrm{~mm}^{-1}(n=5)$ for $10 \%, 30 \%$ and $50 \%$ glucose solutions, respectively, after a period of 180 minutes. The reasons for the high standard deviation for the individual concentrations could be the difference in tissue samples, inhomogeneities in the tissue and other physical parameters. The flat nature of the baseline [Fig. 2(g)] and the constant intensity in the control experiments (Fig. 4) indicate that neither mineral oil nor saline, added in small amount to prevent liquid evaporation, induces any optical clearing properties.

The results from this study indicate that more concentrated solutions of OCAs can induce higher clearing effect in tissues. On the other hand, previous in vivo studies have demonstrated that some short-term and long-term effects of OCAs on blood circulatory system are possible, including stasis of blood flow in vessels. ${ }^{28}$ On the model system, such as blood vessels in chick chorioallantoic membrane, it was shown that short-term (less than $30 \mathrm{~min}$ ) effects of glucose on blood vessels are smaller than those of glycerol, but long-term (two days) effects of glucose are greater. ${ }^{28}$ Therefore, it is very critical to establish the optimal amounts that could be applied for maximal (local) clearing effects and, at the same time, would not cause serious damage to different tissues (in particular application of clearing agents to skin, accompanied blood stasis could be of less importance as for other tissues with a superficial blood vessel structure). That would be the subject for our next studies. 


\section{Conclusion}

In this study we have monitored intensity changes of reflected light from a gold-plated mirror placed below porcine skin. These changes were induced by the addition of various concentrations of glucose due to the effect of optical clearing. We conclude that OCT is capable of continuous monitoring of changes occurring due to optical clearing. Introducing an optical clearing agent to a biological tissue could assist in widening the range of applications of OCT in various studies. This is yet another attempt to resolve the problem of lack of penetration depth within turbid media studied by optical imaging techniques. A higher concentration of an optical clearing agent, for instance, proved to have a higher clearing effect than lower ones, consistent with previous published studies. An optimal concentration of glucose solution must be considered for optical clearing taking into account the time taken for that glucose solution to achieve a required clearing percentage and the osmotic stress it induces on the tissue. Further studies will be performed to quantify the most effective glucose concentration in biological tissues.

\section{Acknowledgments}

This study was supported in part by grants from the Institute of Biomedical Imaging Sciences (IBIS-97708), CRDF (RUB1-2932-SR-08), and NSF (CMMI-0900743). VVT was additionally supported by grants 224014

Photonics4life-FP7-ICT-2007-2; RF Ministry of Science and Education 2.1.1/4989 and 2.2.1.1/2950, Project 1.4.09 of Federal Agency of Education of RF; the RF Governmental contracts 02.740.11.0484 and 02.740.11.0770.

\section{References}

1. Huang D, Swanson EA, Lin CP, Schuman JS, Stinson WG, Chang W, Hee MR, Flotte T, Gregory K, Puliafito CA, Fujimoto JG. Optical coherence tomography. Science. 1991; 254:1178-1181. [PubMed: 1957169]

2. Tomlins PH, Wang RK. Theory, developments and applications of optical coherence tomography. $\mathrm{J}$ Phys D Appl Phys. 2005; 38:2519.

3. Drexler, W.; Fujimoto, JG. Optical Coherence Tomography: Technology and Applications. Springer; New York: 2008.

4. Fercher AF, Mengedoht K, Werner W. Eye-length measurement by interferometry with partially coherent-light. Opt Lett. 1988; 13:186-188. [PubMed: 19742022]

5. Manapuram R, Manne V, Larin KV. Development of phase-stabilized swept-source OCT for the ultrasensitive quantification of microbubbles. Laser Phys. 2008; 18:1080-1086.

6. Larina IV, Sudheendran N, Ghosn MG, Jiang J, Cable A, Larin KV, Dickinson ME. Live imaging of blood flow in mammalian embryos using Doppler swept-source optical coherence tomography. J Biomed Opt. 2008; 13:060506. [PubMed: 19123647]

7. Xu X, Wang RK, Elder JB. Optical clearing effect on gastric tissues immersed with biocompatible chemical agents investigated by near infrared reflectance spectroscopy. J Phys D Appl Phys. 2003; 36:1707.

8. Tuchin, VV. Tissue Optics: Light Scattering Methods and Instruments for Medical Diagnosis. SPIE Press; Bellingham, Washington: 2007.

9. Tuchin, VV. Optical Clearing of Tissues and Blood. SPIE Press; Bellingham, WA: 2005.

10. Larina IV, Carbajal EF, Tuchin VV, Dickinson ME, Larin KV. Enhanced OCT imaging of embryonic tissue with optical clearing. Laser Phys Lett. 2008; 5:476-479.

11. Tuchin VV, Maksimova IL, Zimnyakov DA, Kon IL, Mavlyutov AH, Mishin AA. Light propagation in tissues with controlled optical properties. J Biomed Opt. 1997; 2:401-417.

12. Ghosn MG, Carbajal EF, Befrui NA, Tuchin VV, Larin KV. Differential permeability rate and percent clearing of glucose in different regions in rabbit sclera. J Biomed Opt. 2008; 13:021110. [PubMed: 18465959]

13. Vargas G, Chan EK, Barton JK, HGR, Welch AJ. Use of an agent to reduce scattering in skin. Laser Surg Med. 1999; 24:133-141. 
14. Van Gemert MJC, Jacques SL, Sterenborg HJCM, Star WM. Skin optics. IEEE T Bio Med Eng. 1989; 36:1146-1154.

15. Oldham M, Sakhalkar H, Oliver T, Johnson GA, Dewhirst M. Optical clearing of unsectioned specimens for three-dimensional imaging via optical transmission and emission tomography. $\mathbf{J}$ Biomed Opt. 2008; 13:021113. [PubMed: 18465962]

16. Yoon J, Son T, Choi EH, Choi B, Nelson JS, Jung B. Enhancement of optical skin clearing efficacy using a microneedle roller. J Biomed Opt. 2008; 13:021103. [PubMed: 18465952]

17. Genina EA, Bashkatov AN, Korobko AA, Zubkova EA, Tuchin VV, Yaroslavsky I, Altshuler GB. Optical clearing of human skin: Comparative study of permeability and dehydration of intact and photothermally perforated skin. J Biomed Opt. 2008; 13:021102. [PubMed: 18465951]

18. Vargas G, Chan KF, Thomsen SL, Welch AJ. Use of osmotically active agents to alter optical properties of tissue: Effects on the detected fluorescence signal measured through skin. Laser Surg Med. 2001; 29:213-220.

19. Yeh AT, Choi B, Nelson JS, Tromberg BJ. Reversible dissociation of collagen in tissues. J Invest Dermatol. 2003; 121:1332-1335. [PubMed: 14675178]

20. Larin KV, Ghosn MG, Ivers SN, Tellez A, Granada JF. Quantification of glucose diffusion in arterial tissues by using optical coherence tomography. Laser Phys Lett. 2007; 4:312-317.

21. Ghosn MG, Carbajal EF, Befrui NA, Tellez A, Granada JF, Larin KV. Permeability of hyperosmotic agent in normal and atherosclerotic vascular tissues. J Biomed Opt. 2008; 13:010505. [PubMed: 18315350]

22. Larin KV, Tuchin VV. Functional imaging and assessment of the glucose diffusion rate in epithelial tissues in optical coherence tomography. Quantum Electron. 2008; 38:551-556.

23. Ghosn MG, Sudheendran N, Wendt M, Glasser A, Tuchin VV, Larin KV. Monitoring of glucose permeability in monkey skin in vivo using optical coherence tomography. J Biophotonics. 2010; 3:25-33. [PubMed: 19824024]

24. Zhu D, Wang J, Zhi Z, Wen X, Luo Q. Imaging dermal blood flow through the intact rat skin with an optical clearing method. J Biomed Opt. 2010; 15:026008. [PubMed: 20459253]

25. Liu C, Zhi Z, Tuchin VV, Luo Q, Zhu D. Enhancement of skin optical clearing efficacy using photo-irradiation. Lasers Surg Med. 2010; 42:132-140. [PubMed: 20166162]

26. Wen X, Mao Z, Han Z, Tuchin VV, Zhu D. In vivo skin optical clearing by glycerol solutions: Mechanism. J Biophotonics. 2010; 3:44-52. [PubMed: 19937846]

27. Wen X, Tuchin VV, Luo Q, Zhu D. Controlling the scattering of intralipid by using optical clearing agents. Phys Med Biol. 2009; 54:6917-6930. [PubMed: 19887711]

28. Zhu D, Zhang J, Cui H, Mao Z, Li P, Luo Q. Short-term and long-term effects of optical clearing agents on blood vessels in chick chorioallantoic membrane. J Biomed Opt. 2008; 13:021106. [PubMed: 18465955]

29. Mao Z, Zhu D, Hu Y, Wen X, Han Z. Influence of alcohols on the optical clearing effect of skin in vitro. J Biomed Opt. 2008; 13:021104. [PubMed: 18465953]

30. Zhi Z, Han Z, Luo Q, Zhu D. Improve optical clearing of skin in vitro with propylene glycol as a penetration enhancer. J Innovat Opt Health Sci. 2009; 2:245-251.

31. Tuchin VV, Xu X, Wang RK. Dynamic optical coherence tomography in studies of optical clearing, sedimentation, and aggregation of immersed blood. Appl Opt. 2002; 41:258-271. [PubMed: 11900442] 


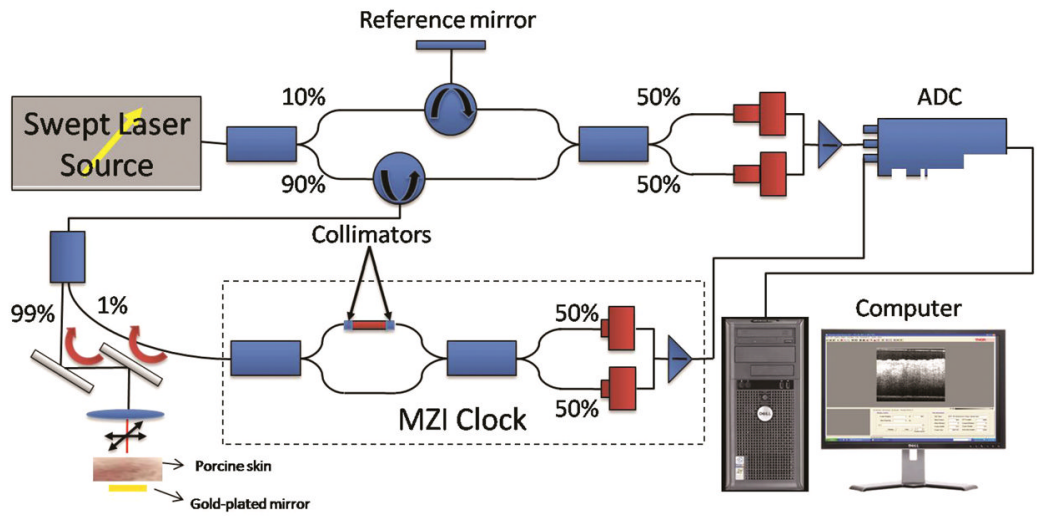

Fig. 1.

A schematic of the SS-OCT (Thorlabs, SL1325) setup. MZI: Mach-Zehnder interferometer; ADC: Analog to digital converter. 

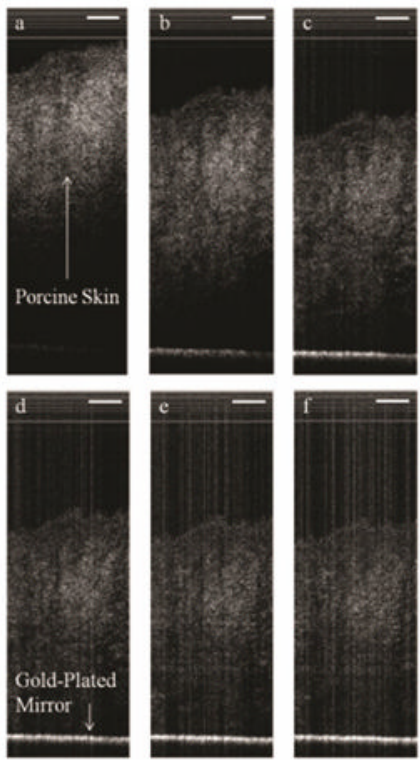

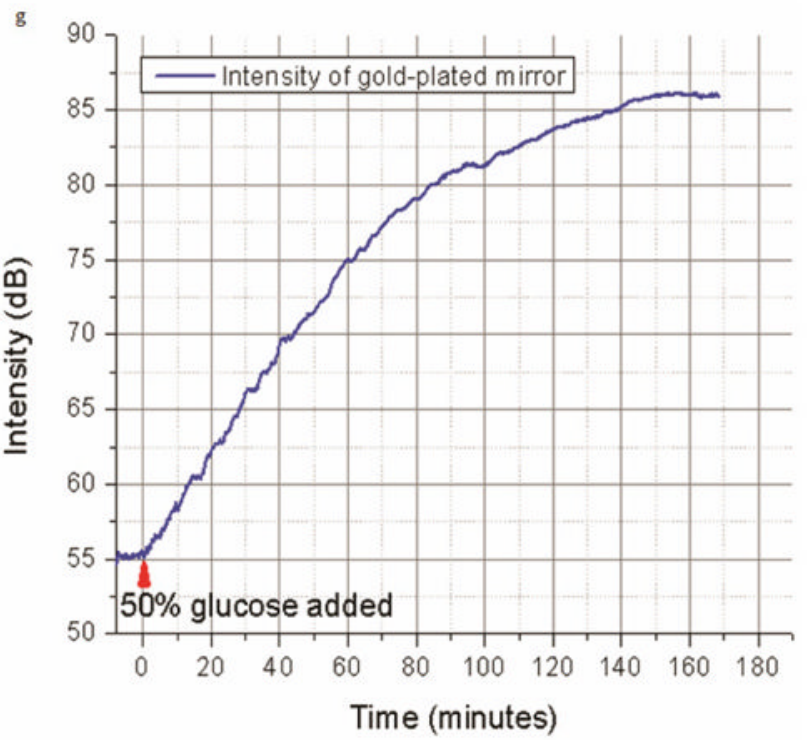

Fig. 2.

Monitoring intensity changes of gold mirror due to optical clearing of porcine skin using $50 \%$ glucose solution. (a) 2D image at the instant of addition of glucose solution. (b)-(f) 2D images acquired after $35,70,105,140$, and 165 minutes from the addition of glucose solution. (g) Intensity of light reflected from the mirror with time. Time $t=0$ minutes corresponds to the time of addition of glucose. Scale bar $=250 \mu \mathrm{m}$. 


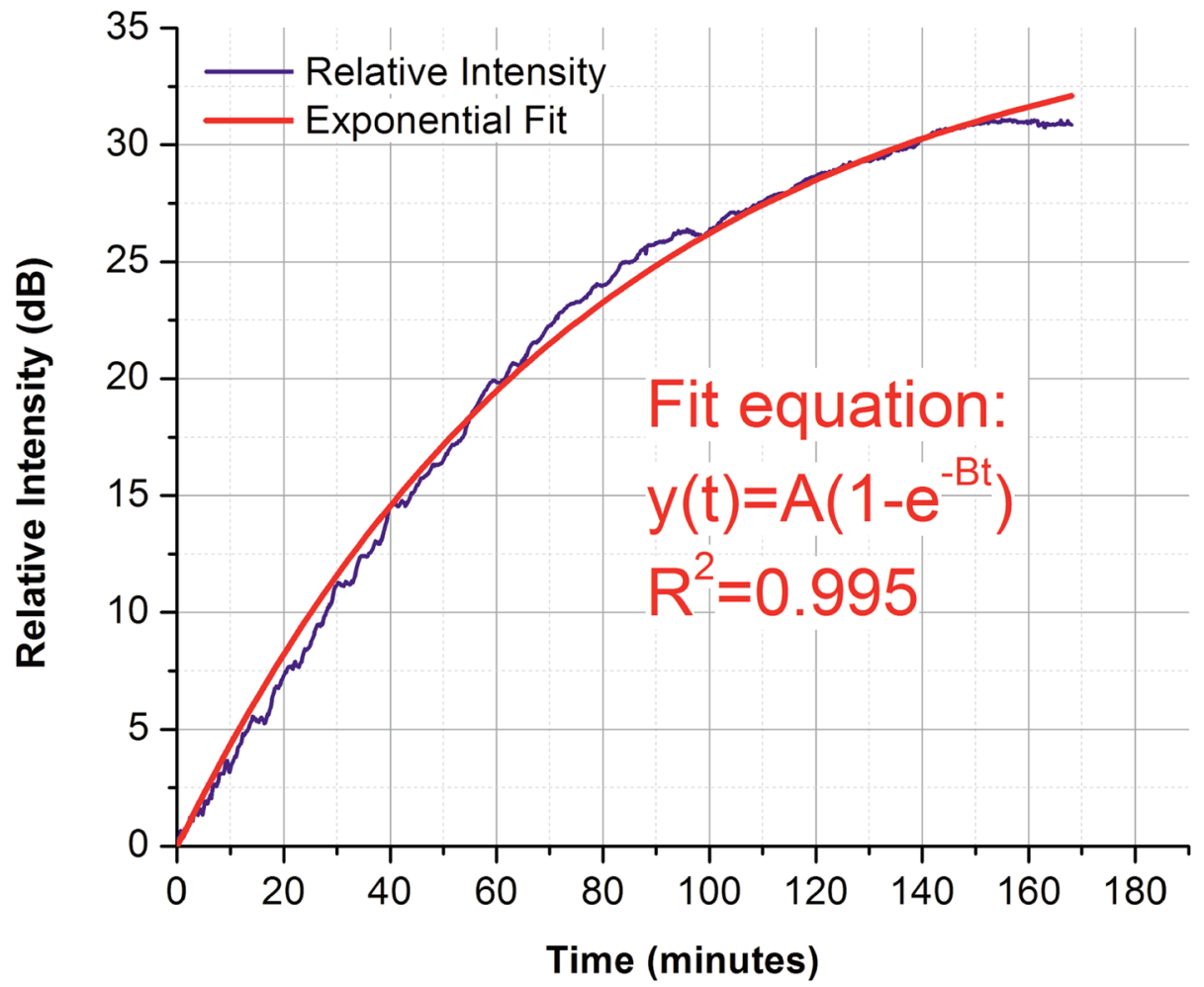

Fig. 3.

Change in OCT signal intensity recorded from gold mirror placed under porcine skin sample during $50 \%$ glucose solution diffusion experiment. 


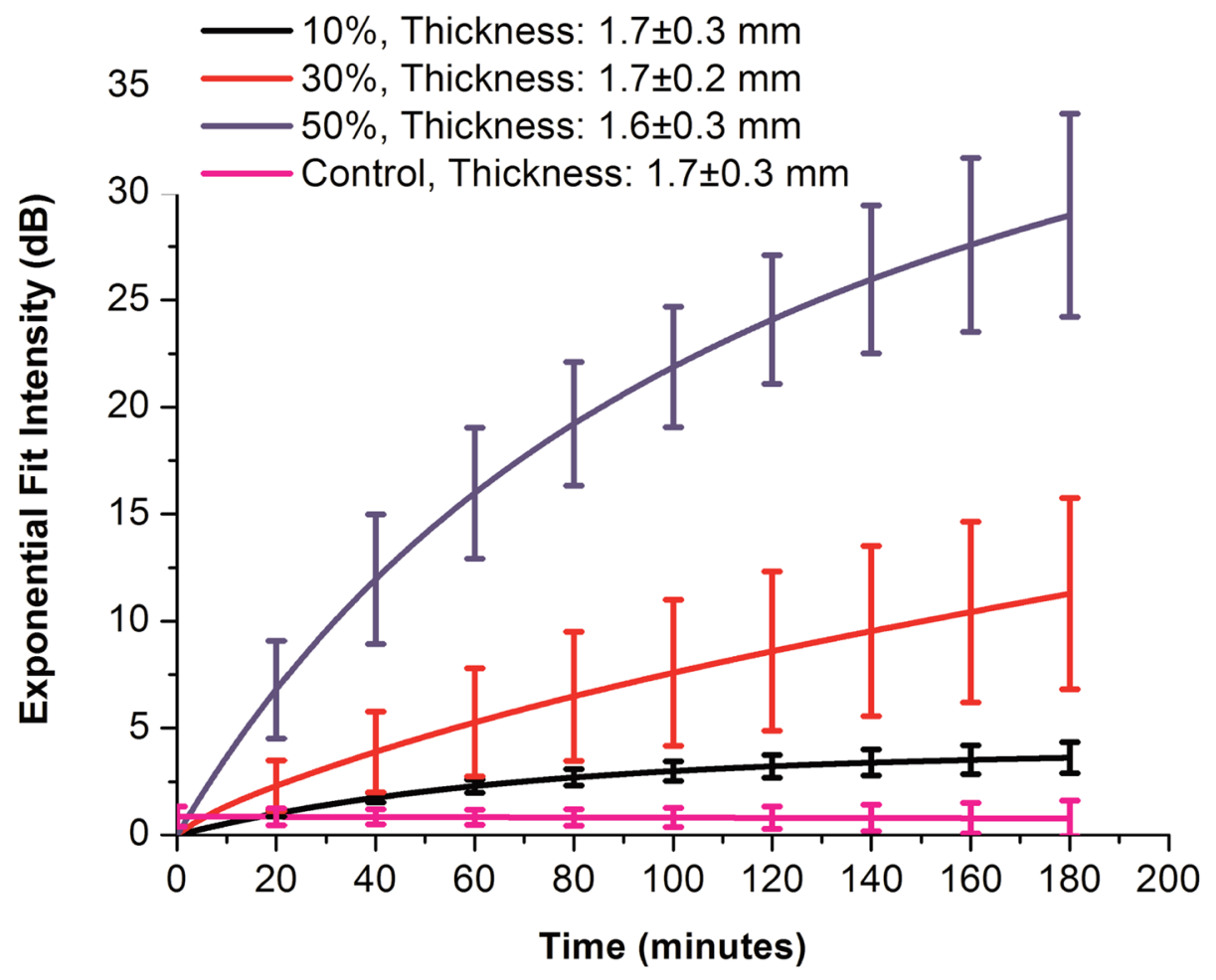

Fig. 4.

The averaged exponential fit for changes in OCT signal intensity of gold mirror placed under porcine skin recorded in control, 10\%, 30\% and 50\% glucose diffusion experiments. 


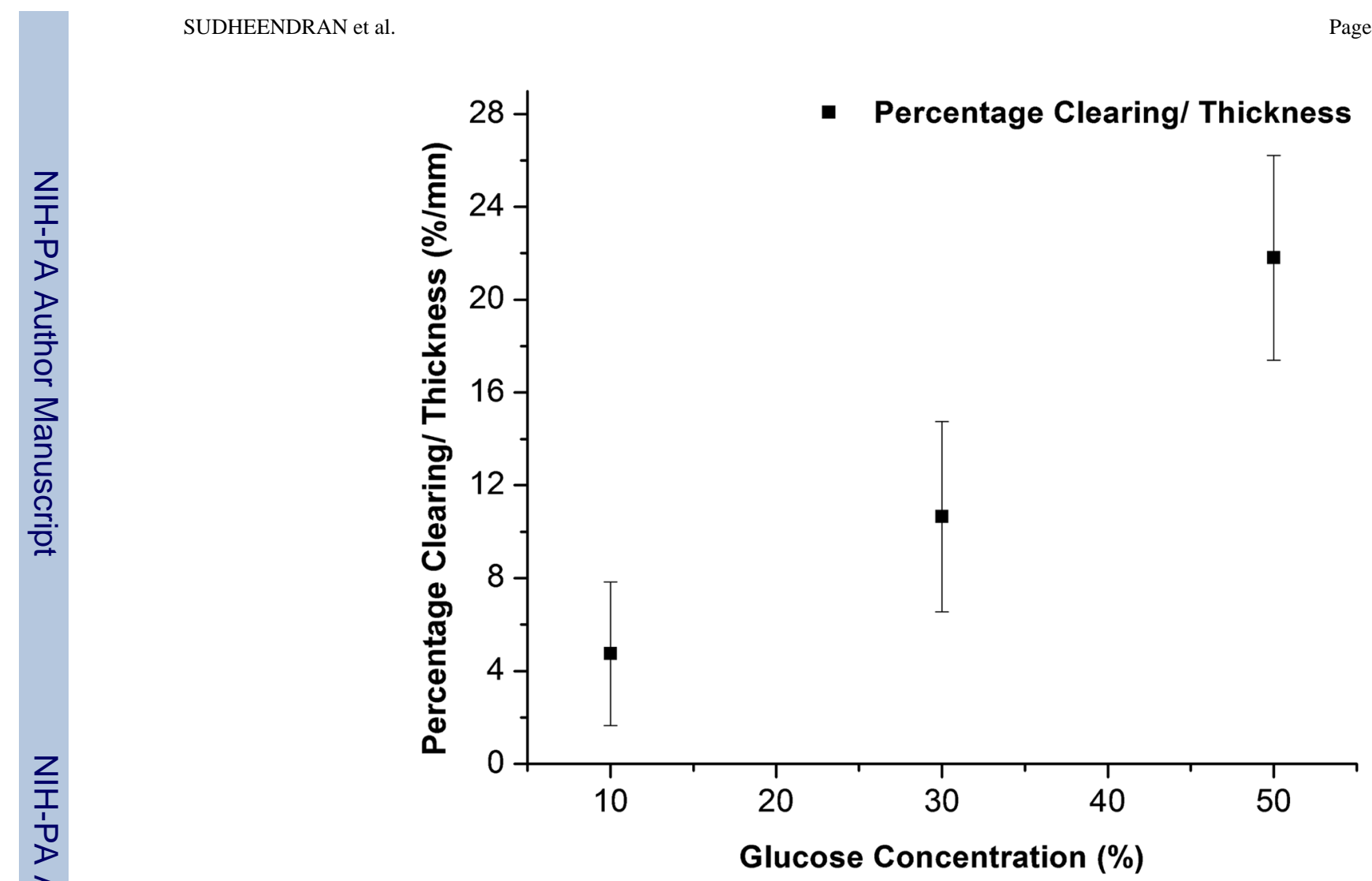

Fig. 5.

Percentage clearing/thickness ratio of $10 \%, 30 \%$ and $50 \%$ glucose solutions in porcine skin. 